\title{
Misdiagnosing multicentric Castleman's disease in an HIV-positive patient
}

Danuel Toscano'

(iD) Sergio Cristina ${ }^{1}$

Datricia Cipriano ${ }^{1}$

Ana Rafaela Alves ${ }^{1}$

1. Hospital de Cascais, Alcabideche, Portugal

\section{INTRODUCTION}

The differential diagnosis of fever and lymphadenopathy in an HIV-positive patient is extensive and complex. Castleman's disease (CD) represents a heterogeneous group of lymphoproliferative disorders, which includes unicentric and multicentric CD (MCD), subdivided into HHV-8-associated MCD, generally in HIV-positive and other immunocompromised individuals, and HHV-8-negative/idiopathic MCD (iMCD), of unknown etiology. Despite significant advances in recent years, the overall understanding of CD remains limited, and formal diagnostic criteria for HHV-8-associated MCD have not been established. Furthermore, since there is significant clinical, histologic, and immunologic overlap with other malignant, autoimmune, and infectious disorders, and given the rarity of CD and the nonspecific nature of its symptoms, a high level of suspicion is required in patients with a compatible clinical picture.
We report the case of a 57-year-old man with HIV infection who presented with recurrent and unexplained fever, lymphadenopathies, and severe pancytopenia.

\section{CASE PRESENTATION}

We describe the case of a 57-year-old male patient with a history of cocaine and heroin use in the past, heavy smoking, drinking and poorly controlled HIV infection for the past 20 years (nadir CD4+ count 500/ $\mu \mathrm{L}$ ), although currently suppressed. He had presented several times in the past 6 years with unexplained recurrent low-grade fever, malaise, anorexia, and night sweats. Physical examination was remarkable for mild hepatosplenomegaly and generalized, infracentimetric, non-tender lymphadenopathies. Analytical findings included sustained pancytopenia and elevated 
inflammatory markers. Blood cultures and viral serologies were repeatedly negative, and bronchoalveolar lavage showed no abnormal findings. Fine needle aspiration biopsies of one axillary and two inguinal nodes showed a reactive pattern. Beta-2-microglobulin was slightly elevated, but immunophenotyping of peripheral blood circulating B cells was normal. Serum immunofixation electrophoresis demonstrated oligoclonal bands (IgG, kappa, and lambda), and bone marrow biopsy revealed mild plasmocytosis (16\%).

A month after the last hospitalization, the patient presented once again with the same complaints and was admitted for study. Physical examination and blood work remained unchanged (Table 1). Bone marrow examination was repeated, which confirmed mild plasmocytosis, with no other atypical findings. Hence, the combined findings of fever, lymphadenopathy, hepatosplenomegaly, and severe cytopenias along with plasma cell disorder led to a suspicion of MCD. HHV-8 DNA was detected in the plasma through quantitative real-time PCR, and an excisional biopsy of an axillary node was performed, revealing an increased number of follicles, of variable morphology, penetrated by hyalinized blood vessels ("lollipop appearance") and with concentric rimming of mantle zone lymphocytes, arranged in an "onion skin" fashion (Figure 1), as well as HHV-8 infection (Figure 2), compatible with a plasmablastic variant of MCD. The patient was referred to the Hematology Department and initiated on rituximab $375 \mathrm{mg} / \mathrm{m}^{2}$ and etoposide $100 \mathrm{mg} / \mathrm{m}^{2}$ for 4 weeks, with significant clinical and analytical improvement. No serious adverse events of therapy occurred. At 12-month follow-up, the patient remains asymptomatic, with a considerable decrease in the size of all adenopathies and normalized blood counts.

\section{DISCUSSION}

HHV-8 infects B cells and plasmablasts and is present in up to 10 to $30 \%$ of mantle zone lymphoid cells of HHV-8-associated MCD' ${ }^{1}$. Human IL-6 and viral IL-6 are important drivers of B cell proliferation by activating the human IL-6 receptor (gp130) and inducing VEGF expression in interfollicular areas and, consequently, cause the symptoms observed, particularly during lytic infection ${ }^{2}$. Immunohistochemistry for LANA-1 in the lymph node is the gold standard for HHV-8 detection, and excisional biopsy should be performed if initial exams fail to confirm the diagnosis and clinical suspicion remains high, as in this case.

The epidemiology of CD is difficult to characterize accurately, given its rarity and clinical heterogeneity $^{3}$. Due to unknown reasons, among HIV-infected individuals, the incidence of CD has increased over



FIGURE 1.

LYMPHOID

FOLLICLES WITH

EXPANDED MANTLE

ZONE WITH A

CONCENTRIC

APPEARANCE

(H\&E X100) 


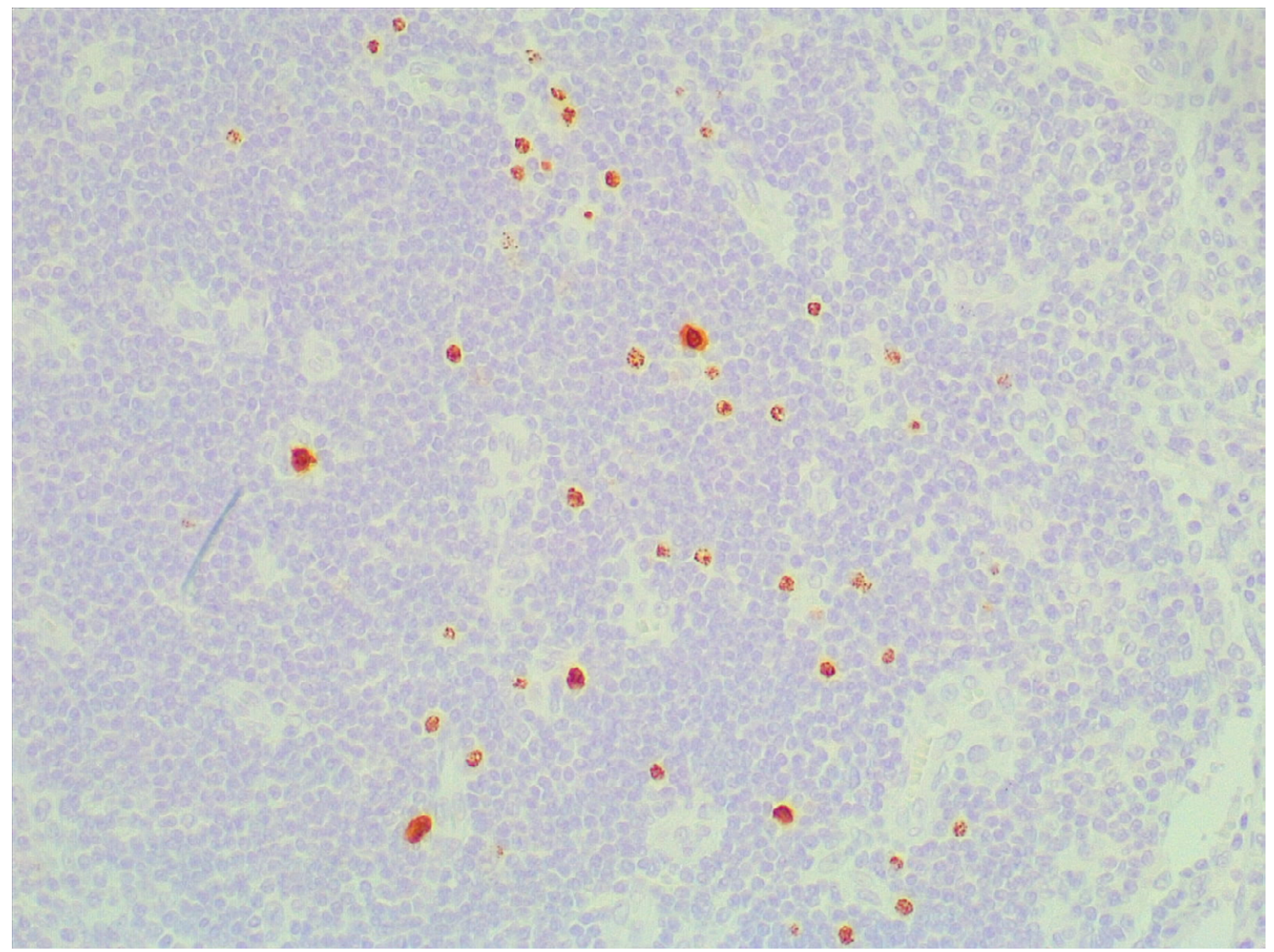

FIGURE 2. IMMUNOHISTOCHEMISTRY SHOWING PLASMABLASTS POSITIVE FOR HHV-8 LANA-1

TABLE 1. BIOCHEMICAL DATA ON ADMISSION, AT DISCHARGE, AND AT 6-MONTH FOLLOW-UP

\begin{tabular}{|c|c|c|c|c|}
\hline & On admission & At discharge & Follow-up & Reference values \\
\hline Hemoglobin (g/dL) & 6.2 & 8.2 & 11.4 & $13-17$ \\
\hline Hematocrit (\%) & 24 & 26 & 36 & $40-50$ \\
\hline Reticulocyte index & 0.9 & 1.2 & - & $1-3 \%$ \\
\hline Platelets $(103 / \mu \mathrm{L})$ & 36 & 144 & 175 & $150-350$ \\
\hline WCC $(103 / \mu L)$ & 4.3 & 5.4 & 5.2 & $4.5-11.4$ \\
\hline LUC (\%) & 11 & - & - & - \\
\hline Serum iron $(\mu \mathrm{g} / \mathrm{dL})$ & 38 & - & 94 & $60-170$ \\
\hline Ferritin $(\mathrm{ng} / \mathrm{mL})$ & 1366 & - & 579 & $20-250$ \\
\hline Transferrin (mg/dL) & 67 & - & 75 & $170-370$ \\
\hline Folic acid $(\mathrm{ng} / \mathrm{mL})$ & 20.7 & - & - & $2.7-17$ \\
\hline Vitamin B12 (pg/mL) & 509 & - & - & $160-950$ \\
\hline Sodium (mEq/L) & 130 & 141 & 143 & $136-146$ \\
\hline Potassium (mEq/L) & 4.0 & 4.0 & 4.2 & $3.5-5.1$ \\
\hline Calcium $(\mathrm{mg} / \mathrm{dL})^{*}$ & 8.3 & 8.5 & 8.4 & $8-10$ \\
\hline Lactate dehydrogenase (UI/L) & 82 & 97 & 90 & $105-330$ \\
\hline Urea $(\mathrm{mg} / \mathrm{dL})$ & 95 & 48 & 39 & $18-55$ \\
\hline Creatinine (mg/dL) & 1.7 & 0.8 & 0.8 & $0.7-1.25$ \\
\hline Total bilirubin (mg/dL) & 0.9 & 0.9 & 0.5 & $<1.2$ \\
\hline Alkaline phosphatase (UI/L) & 52 & 52 & 46 & $20-140$ \\
\hline Albumin (g/dL) & 2.3 & 2.5 & 3.0 & $3.5-5.0$ \\
\hline $\operatorname{ESR}(\mathrm{mm} / \mathrm{h})$ & 76 & 65 & 20 & $<20$ \\
\hline PCR (mg/dL) & 14 & 2 & 1.1 & $<0.5$ \\
\hline Beta-2-microglobulin & 6.8 & - & - & $1.1-2.4$ \\
\hline
\end{tabular}


the years since the introduction of antiretroviral ther$\mathrm{apy}^{4}$. The course of the disease may be variable, from a slow onset over a few years to a rapidly progressive illness that can lead to death in a few weeks. However, in HIV-positive patients, HHV-8-associated MCD tends to follow an acute course, and risk factors in these individuals include increased age ( $>33$ years), non-Caucasian ethnicity, no previous ART exposure, and nadir CD4+ count $>200 / \mu L^{5}$. The prognosis of untreated HHV-8-associated MCD is poor ${ }^{6,7}$, and rituximab-based approaches, alone or in combination with chemotherapy (generally intravenous etoposide or liposomal doxorubicin), are currently the mainstay of treatment. These have dramatically improved survival and reduced the risk of associated lymphomas, including in the setting of multiply relapsed disease $^{8-11}$, which may be predicted by rising levels of plasma HHV8 DNA ${ }^{12}$. Antiretroviral therapy should also be started or continued in all patients since the reduction in viral load and improvement in immune function result in better tolerance of chemotherapy, fewer opportunistic infections, and improved overall outcome.

\section{CONCLUSION}

Due to its rarity and nonspecific manifestations, HHV-8 associated multicentric Castleman's disease remains an elusive diagnosis, but one to be considered, especially when unexplained fever and adenopathies are present. Further studies and the introduction of formal diagnostic criteria would represent an important step in aiding clinicians to diagnose this disease more frequently and in earlier stages.

\section{Author's Contributions}

Manuel Toscano: Conception and design of the work, acquisition of data, drafting and revising the work critically for important intellectual content and final approval of the version to be published. Sergio Cristina: Conception of the work, revising the work critically for important intellectual content and final approval of the version to be published. Patricia Cipriano: Conception of the work, revising the work critically for important intellectual content and final approval of the version to be published. Ana Rafaela Alves: Revising the work critically for important intellectual content and final approval of the version to be published.

\section{REFERENCES}

1. Dupin N, Fisher C, Kellam P, Ariad S, Tulliez M, Franck N, et al. Distribution of human herpesvirus-8 latently infected cells in Kaposi's sarcoma, multicentric Castleman's disease, and primary effusion lymphoma. Proc Natl Acad Sci U S A. 1999;96(8):4546-51.

2. Uldrick TS, Polizzotto MN, Yarchoan R. Recent advances in Kaposi sarcoma herpesvirus-associated multicentric Castleman disease. Curr Opin Oncol. 2012;24(5):495-505.

3. Munshi N, Mehra M, van de Velde H, Desai A, Potluri R, Vermeulen J. Use of a claims database to characterize and estimate the incidence rate for Castleman disease. Leuk Lymphoma. 2015;56(5):1252-60.

4. Bower M, Newsom-Davis T, Naresh K, Merchant S, Lee B, Gazzard B, et al. Clinical features and outcome in HIV-associated multicentric Castleman's disease. J Clin Oncol. 2011;29(18):2481-6.

5. Powles T, Stebbing J, Bazeos A, Hatzimichael E, Mandalia S, Nelson M, et al. The role of immune suppression and HHV-8 in the increasing incidence of HIV-associated multicentric Castleman's disease. Ann Oncol. 2009;20(4):775-9.

6. Frizzera G, Peterson BA, Bayrd ED, Goldman A. A systemic lymphoproliferative disorder with morphologic features of Castleman's disease: clinical findings and clinicopathologic correlations in 15 patients. | Clin Oncol. 1985;3(9):1202-16.

7. Weisenburger DD, Nathwani BN, Winberg CD, Rappaport H. Multicentric angiofollicular lymph node hyperplasia: a clinicopathologic study of 16 cases. Hum Pathol. 1985;16(2):162-72.

8. Uldrick TS, Polizzotto MN, Aleman K, Wyvill KM, Marshall V, Whitby D, et al. Rituximab plus liposomal doxorubicin in HIV-infected patients with KSHV-associated multicentric Castleman disease. Blood. 2014;124(24):3544-52.

9. Pria $A D$, Pinato D, Roe J, Naresh K, Nelson M, Bower M. Relapse of HHV8-positive multicentric Castleman disease following rituximab-based therapy in HIV-positive patients. Blood. 2017;129(15):2143-7.

10. Bower M. How I treat HIV-associated multicentric Castleman disease. Blood. 2010;116(22):4415-21.

11. Oksenhendler E, Boutboul D, Fajgenbaum D, Mirouse A, Fieschi C, Malphettes $M$, et al. The full spectrum of Castleman disease: 273 patients studied over 20 years. Br J Haematol. 2018;180(2):206-16.

12. Stebbing J, Adams C, Sanitt A, Mletzko S, Nelson M, Gazzard B, et al. Plasma HHV8 DNA predicts relapse in individuals with HIV-associated multicentric Castleman disease. Blood. 2011;118(2):271-5. 